\title{
AS INTERPRETAÇÕES DO VERBO 'DAR' E SUA ESTRUTURA TEMÁTICA: UMA ANÁLISE SINTÁTICO-SEMÂNTICA
}

\author{
Thayse Letícia FERREIRA ${ }^{1}$ \\ Amanda Pontes RASSI ${ }^{2}$ \\ Renato Miguel BASSO ${ }^{3}$
}

\begin{abstract}
Resumo: Neste artigo, apresentamos uma proposta de análise de algumas das várias interpretações possíveis do verbo 'dar', baseada nos conceitos de papéis temáticos e de hierarquia temática. Nossa análise permite dar conta de uma gama considerável de interpretações desse verbo, por meio de ferramentas independentemente motivadas, considerando uma grade temática básica para ele e uma hierarquia que permite gerar outras interpretações além daquela canônica, com três argumentos. Ao final, relacionamos nossa proposta com algumas estruturas fixas e semifixas do verbo 'dar'.
\end{abstract}

Palavras-chave: Papéis temáticos. Hierarquia temática. Semântica do verbo.

\section{Introdução}

O verbo 'dar' aparece em construções sintáticas bastante diversificadas e apresenta significados também bastante distintos no português brasileiro (PB). Dado que ele pode ser classificado como um verbo pleno, auxiliar, suporte, leve, etc., poderíamos facilmente suspeitar de que estamos diante de algum tipo de polissemia ou ambiguidade lexical. Neste texto, contudo, defenderemos que vários dos usos do verbo 'dar' podem ser explicados a partir de: (i) um significado verbal básico, que atribui certos papéis temáticos

\footnotetext{
${ }^{1}$ UFSCar - Universidade Federal de São Carlos - Programa de Pós-graduação em Linguística. São Carlos - São Paulo - Brasil. 13565-905 - tleticiaf@gmail.com

${ }^{2}$ UFSCar - Universidade Federal de São Carlos - Programa de Pós-graduação em Linguística. São Carlos - São Paulo - Brasil. 13565-905 - amandarassi85@gmail.com

${ }^{3}$ UFSCar - Universidade Federal de São Carlos - Programa de Pós-graduação em Linguística/CNPq. São Carlos - São Paulo - Brasil. 13565-905 - rmbasso@gmail.com

http://dx.doi.org/10.21165/gel.v14i2.1724
} 
a seus complementos; (ii) uma grade temática particular; e (iii) uma teoria mínima de "hierarquia temática", que trata da atribuição e da ordenação sintático-cartográfica dos papéis temáticos. Com nossa análise, argumentaremos que é possível dar conta, a partir de noções independentemente motivadas, de uma grande quantidade de usos do verbo 'dar', evitando apelos à proliferação de significados ou a ambiguidades.

Para tanto, o presente artigo se organiza da seguinte forma: a seção a seguir apresenta a metodologia utilizada para a obtenção e análise dos dados; a seção "Sobre os significados do verbo 'dar'” expõe não exaustivamente os vários significados que podem ser atribuídos a esse verbo; a seção "Uma proposta para a base sintático-semântica do verbo 'dar"' apresenta uma proposta de análise baseada em papéis temáticos e na hierarquia temática; a seção "Analisando os exemplos" coloca em teste nossa proposta, através da análise de exemplos relevantes. Por fim, retomaremos o percurso feito e faremos um balanço dos resultados na Conclusão.

\section{Metodologia}

O desenvolvimento desta pesquisa passa por duas grandes etapas distintas: a) a de obtenção dos dados a serem investigados e b) a de análise desses dados com base em uma nova proposta de interpretação sintático-semântica do verbo 'dar'. Para justificar a escolha deste verbo em questão e assim validar a relevância da pesquisa, fizemos uma busca por frequência dos verbos mais comuns da língua portuguesa e encontramos o verbo 'dar' entre os dez verbos mais frequentes, junto a 'ser', 'ter', 'estar', 'fazer', 'poder', 'ir', 'dizer', 'haver' e 'dever'. Para realizar esse levantamento, buscamos os lemas verbais mais recorrentes em todos os corpora escritos de português do Brasil e de Portugal, disponíveis no AC/DC (Acesso a Corpus/Disponibilização de Corpus). A busca pode ser reproduzida através do endereço $<\underline{\mathrm{http}}$ ://inguateca.pt/ACDC/>.

Tendo definido a unidade lexical a ser investigada, partimos para a obtenção dos dados a serem analisados ao longo deste trabalho, que são as diferentes construções sintático-semânticas que envolvem o verbo 'dar', ou seja, esse verbo dentro do contexto de uma frase simples, elementar, que contenha sua rede argumental básica. Assim, as construções a serem analisadas adiante são exemplos construídos, no limite de uma frase simples, que contenham todos (e, ao mesmo tempo, apenas) os seus argumentos 
essenciais. Para definir quais são os argumentos essenciais de cada construção sintáticosemântica, partimos das acepções que diferentes dicionários trazem para as construções com o verbo 'dar'. Investigamos as entradas desse verbo em dicionários de referência do português, tais como: Michaelis (1998), Houaiss (2001), Aurélio (FERREIRA, 1999), Dicionário Online do Português (Dicio), Priberam online e Dicionário gramatical de verbos (1991). Na seção "Sobre os significados do verbo 'dar'”, apresentaremos a abordagem que cada um desses dicionários traz em relação ao verbo 'dar'.

Para a etapa de análise dos dados, utilizamos como aparato teórico a Sintaxe de Primeira Fase desenvolvida por Ramchand (2008) no âmbito da Nanossintaxe (STARKE, 2009). Na seção "Uma proposta para a base sintático-semântica do verbo 'dar'”, discutimos, primeiramente, os vários problemas encontrados na literatura sobre papéis temáticos e, posteriormente, defendemos que um modelo como aquele proposto por Ramchand (2008) pode ser mais produtivo para a análise das línguas naturais, pois não assume a necessidade de se mapear os argumentos do predicado de um nível léxicosemântico para um nível sintático. Nessa teoria, os argumentos do verbo são inseridos diretamente em posições sintáticas (spec-XP), que licenciam sua interpretação semântica localmente. Como no modelo há uma composição sintática bastante rígida, governada por regras de localidade, os diferentes usos de um determinado verbo podem ser explicados por diferentes composições temáticas, que dependerão especialmente da posição que os argumentos ocupam na estrutura.

Ao explorar esse modelo, defendemos que as diferentes construções com o verbo 'dar' são derivadas de uma única grade contendo três argumentos: um argumento "iniciador" (INITIATOR) da eventualidade, um argumento que atua no evento como “tema" (UNDERGOER) e, por fim, um argumento "resultante" (RESULTEE) que é ou o beneficiário da situação descrita pelo verbo ou o resultado final de uma determinada transição. Devido à existência de certas regras, tais como a de subassociação de itens, o "Princípio de Localidade" e a Condição de Âncora (CAHA, 2009), a estrutura mais básica do verbo 'dar' é aquela que contém todos os três papéis, sendo dela derivadas uma estrutura com dois papéis (UNDERGOER > RESULTEE) e uma com apenas um papel (RESULTEE), encontrada, sobretudo, em usos impessoais do verbo sob análise, como "deu ruim" e "deu duas horas". 
Com isso, esperamos demonstrar que não há necessidade de se apelar à proliferação de significados ou a ambiguidades para explicar os diferentes usos do verbo 'dar'. Com uma teoria temática diretamente ligada ao componente sintático da gramática, é possível elaborar uma análise mais ampla para os diferentes usos desse verbo, que explora noções caras às teorias linguísticas modernas, tais como os conceitos de hierarquia e localidade.

\section{Sobre os significados do verbo 'dar'}

Nesta seção, apresentaremos alguns dos significados atualmente encontrados no português brasileiro para o verbo 'dar'. Começaremos, na próxima subseção, apresentando as definições e acepções do verbo 'dar' nos dicionários indicados na seção anterior. Na subseção seguinte, trataremos daquelas que são as estruturas e interpretações mais frequentes nas quais esse verbo é encontrado.

\section{Classificação do verbo ‘dar’ em dicionários}

Nesta seção, apresentaremos um levantamento das acepções que cada dicionário traz para o verbo 'dar', bem como sua classificação sintática e, por vezes, semântica. O objetivo não é fazer um levantamento exaustivo dessas construções nos dicionários nem avaliar em profundidade cada uma das definições trazidas por eles, mas basicamente apresentar algumas abordagens, por vezes incoerentes, inconsistentes ou contraditórias, a fim de justificar a necessidade de um trabalho sistemático como o que propomos neste artigo.

Como notamos, o verbo 'dar', por ser um dos verbos mais produtivos do português, apresenta funcionamento bastante diversificado e aparece em construções com diferentes estruturas sintáticas. De maneira geral, os dicionários e outros produtos lexicográficos da língua portuguesa apresentam como primeira acepção do verbo 'dar' um predicado dativo, que veicula a transferência de um objeto por parte de um doador a um beneficiário. Assim, configura-se como um verbo bitransitivo que exige três argumentos: o agente, o tema e o beneficiário, como se apresenta em: 
(1) Ana deu uma bicicleta para o Rui.

Além dessa acepção básica, os dicionários utilizam diferentes critérios para classificar e definir as diversas construções com o verbo 'dar'.

O dicionário Michaelis (1998), por exemplo, apresenta 59 acepções para o verbo 'dar', classificadas sintaticamente pela transitividade do verbo, além de cerca de 220 expressões fixas: (i) há 40 acepções do verbo 'dar' como transitivo direto, tais como, ceder gratuitamente, fazer doação de (Deu toda a roupa do falecido), entregar (Dar o seu a seu dono), apresentar, oferecer ( $O$ sacerdote deu o crucifixo a beijar), informar, participar (Boas noticias lhe darei), ser sorteado na loteria ou em outros jogos (Deu o número 25, isto é, deu a vaca), dentre várias outras; (ii) há outras 12 acepções do mesmo verbo como transitivo indireto, tais como, encontrar, topar (Ao virar a esquina, deu de cara com o tal homem), acertar, atinar (Não lhe foi possível dar com a significação da charada), notar, perceber (Ainda não deu pela coisa), arremessar, atirar, fazer bater (Deu com a traseira do carro no parapeito), castigar corporalmente, bater (Dava no filho, por este não querer estudar), dentre outras; (iii) há 7 acepções como verbo pronominal, com significados de entregar-se (Deram-se primeiramente ao Senhor), aplicar-se (Dava-se inteiramente aos divertimentos e passatempos), combinar-se (Os dois amigos dão-se muito bem), considerar-se (A mesma justiça se pudera dar por satisfeita), acontecer (Deuse ali um caso interessante), importar (Pouco se me dá disso), declarar-se (dar-se por vencido); (iv) apresenta uma acepção como verbo intransitivo, com o significado de soar (horas) (Deram sete horas no campanário); e (v) uma como verbo transitivo indireto e verbo intransitivo, com o significado de bastar, chegar, ser suficiente (Seu ordenado mal dá para sustentar a família).

O dicionário Houaiss (2001) também faz uma classificação sintática, com base principalmente na transitividade do verbo, mas também na sua valência e regência verbais, classificando o verbo 'dar' como: (i) bitransitivo, com inúmeros significados, tais como pôr na posse de, entregar, presentear, pôr à disposição de, oferecer, conceder, recusar, negar, tornar possível, permitir, dentre vários outros; (ii) transitivo direto e bitransitivo, como nos casos de fazer doação de algo para pessoa ou instituição, ou de realizar ou promover evento, ou ainda de passar uma informação ou ordem; (iii) transitivo direto, com os significados de gerar, produzir (Vacas dão leite), apresentar (Dar 
explicação), emitir, soltar (Dar um grito), passar, aplicar (uma demão de tinta), bater, soar (O relógio deu uma hora), infestar-se de (uma praga, por exemplo); (iv) transitivo direto predicativo, com o sentido de ter na conta de, considerar (Deu o atropelado como morto); (v) verbo intransitivo, com o sentido de caber ( $O$ armário não dá aqui); (vi) transitivo indireto, indicando ser suficiente para, bastar (O dinheiro não dá para comprar o carro), ou dar golpes em, bater (Deu muito no cavalo); e, por fim, (vii) pronominal, com o sentido de acontecer, ocorrer ( $O$ fato deu-se ontem) ou de ter contato com, relacionar-se (Dá-se com os vizinhos). Além dessa classificação básica, o Houaiss ainda apresenta inúmeros casos de expressões fixas e outras construções particulares desse verbo.

O dicionário Aurélio (FERREIRA, 1999) também usa o mesmo tipo de classificação sintática dos outros dicionários, com base principalmente na transitividade do verbo e é um dos que apresenta maior número de acepções. O Aurélio indica, ao todo, 96 significados diferentes para o verbo 'dar', o que contempla inclusive construções causativas, construções com verbo-suporte, expressões modais e expressões fixas, além dos vários significados de 'dar' como verbo pleno, distribucional, seja ele transitivo direto, indireto ou bitransitivo. O primeiro tipo apresentado pelo Aurélio é de verbo transitivo direto, com os significados de ceder, presentear, doar (Deu a biblioteca), ou de produzir, gerar (Dar frutos), de infligir, impor (Dar castigo), de transmitir (dar recado), divulgar ( $O$ rádio deu a notícia), de causar (Sua tristeza me deu pena), dentre outros. Como exemplos de verbo transitivo indireto, o Aurélio indica significados como pagar (Quanto deu pela casa?), chegar, bastar (O dinheiro deu para os gastos), resultar (Nosso esforço deu em nada), ou ter jeito, vocação (Não dou para isso), dentre outros. Como verbo intransitivo, considera o verbo 'dar' como sinônimo de ser sorteado em jogo (Que bicho deu hoje?) ou de adaptar-se (Não me dou com o frio).

O Dicionário Online de Português (Dicio) ${ }^{4}$ também parte de uma classificação sintática com base na transitividade do verbo e indica seis tipos de construções: (i) como verbo bitransitivo, o Dicio aponta nove acepções, tais como oferecer, transferir, vender, pagar, recompensar, gerar, atribuir novo aspecto a algo ou alguém e estar infestado por; (ii) como verbo transitivo indireto, aponta um único uso informal de ter relações sexuais com (Ela dava para o marido); (iii) como verbo transitivo direto e bitransitivo, com os sentidos de promover; organizar alguma coisa (Deu uma festa ao pai), comunicar, fazer

\footnotetext{
${ }^{4}$ Disponível online em: $<$ http://www.dicio.com.br/dar/>.
} 
uma notificação (Deram informação aos turistas), oferecer um sacramento (deram a comunhão aos crismandos) e provocar, ser a razão de ( $O$ álcool lhe dava ânsia); (iv) como verbo transitivo direto, com os significados de receber notícia (Deu no jornal que o Brasil vai crescer), desenvolver; fazer certa atividade (Deu um salto), emitir sons (Deu berros) e ser o valor final de uma operação (10 menos 2 dão 8); (v) como verbo transitivo direto e predicativo, com o sentido de levar em consideração (Deram o bandido como perigoso); e (vi) como verbo pronominal, com os sentidos de sentir (Deu-se bem na vida) e acontecer (A festa deu-se na semana passada).

O Priberam ${ }^{5}$, por sua vez, não faz distinção entre transitivo direto e indireto, mas organiza os significados do verbo 'dar' nas seguintes categorias: (i) verbo transitivo, com 44 significados diferentes; (ii) verbo transitivo e intransitivo, como sinônimo de combinar, condizer (Essa cortina não dá com a decoração da sala); (iii) verbo transitivo e pronominal, com o significado de considerar, julgar (Deu o trabalho por terminado); (iv) verbo intransitivo, com significados de funcionar (O televisor não dá) ou de acontecer (Há pouco deu uma chuvada); (v) verbo pronominal, com 11 significados diferentes; e ainda como (vi) verbo copulativo, com o sentido de tornar-se (Ela deu uma boa profissional).

Os dicionários consultados apresentam algumas inconsistências, que são próprias de trabalhos lexicográficos muito extensos, sobretudo naqueles que são feitos por grandes equipes. Além das inconsistências internas a cada dicionário, também percebemos diferenças de classificação entre estruturas que são muito semelhantes. Para citar um exemplo, o dicionário Houaiss e o Dicio chamam de verbo transitivo direto predicativo o verbo 'dar' em Deu o atropelado como morto e Deram o bandido como perigoso. O Priberam, por sua vez, chama de verbo transitivo pronominal uma estrutura muito semelhante (Deu o trabalho por terminado), ao passo que o Michaelis designa esse verbo, em uma construção parecida (A mesma justiça se pudera dar por satisfeita), como verbo pronominal.

O fato de o verbo 'dar' ser muito produtivo e entrar em construções muito variadas, do ponto de vista tanto sintático quanto semântico, também favorece a existência de inconsistências muitas vezes internas, dentro de um mesmo dicionário. Muitas vezes, os problemas encontrados nas definições desses dicionários se dão por

\footnotetext{
${ }^{5}$ Disponível online em: $<\underline{\text { http:} / / w w w . p r i b e r a m . p t / d l p o / d a r ~}>$.
} 
algum tipo de superespecificação de significados, sem o intuito de buscar um significado ou estrutura básicos dos quais várias interpretações podem surgir. Este trabalho, por outro lado, propõe uma análise exatamente nessas linhas, que parte de uma estrutura de base que teria dado origem a muitas das construções apresentadas pelos dicionários.

\section{Os vários usos do verbo 'dar'}

A análise apresentada na seção de metodologia revela que o verbo 'dar' está entre os dez verbos mais frequentes da língua portuguesa, e tal frequência reflete também a grande diversidade e complexidade de suas construções sintático-semânticas. Rassi e Vale (2013) propuseram uma classificação dessas construções em seis categorias distintas: como verbo pleno, verbo-suporte, verbo causativo, em construções gramaticais, em expressões cristalizadas e em provérbios.

Essa classificação parte do pressuposto de que as construções passam por um continuum verbal (NEVES, 1996), que vai desde a construção mais livre, com significado pleno, até a construção mais fixa, em que o verbo perde traços de seu significado lexical ${ }^{6}$. Nesse sentido, existem os verbos tipicamente plenos, os verbos tipicamente suporte, os tipicamente causativos e assim por diante, porém existe também um conjunto de construções residuais que estão na fronteira entre uma classe e outra. Essas fronteiras não podem ser determinadas por meio de limites exatos.

Vale (2001, p. 27-28) esclarece esse continuum por meio da sequência de exemplos que vai desde o verbo pleno (2), passando por construções com verbo-suporte em diferentes níveis (3), (4), (5), (6) e (7) ${ }^{7}$ até expressão cristalizada mais e menos permutável (8) e (9):

(2) O presidente Muammar Khaddafi deu US\$ 1 bilhão a Farrakhan em 1996.

(3) A comerciante invadiu a avenida e deu um abraço no líder.

\footnotetext{
${ }^{6}$ Segundo Gross (1982, p. 160), esse continuum pode ser estendido até a expressão cristalizada: “[...] a delimitação não é simples de traçar, pois sintaticamente parece existir um continuum entre as formas fixas e as livres". Neves (1996) também trata desse continuum entre construções livres e construções com verbosuporte.

${ }^{7}$ Os diferentes níveis de construções com verbo-suporte têm a ver com a aplicação de testes sintáticos, como, por exemplo: possibilidade de permuta por outros verbos-suporte; permuta de determinantes; transparência e opacidade da construção; fixidez ou não do verbo; dentre outros.
} 
(4) Conde falou da transformação do Rio e deu garantias da melhora da infraestrutura.

(5) Pont deu início ao terceiro mandato consecutivo do PT na capital gaúcha.

(6) Pessoas ligadas ao ex-prefeito afirmaram que ele dava prioridade ao iogurte.

(7) [...] no Cairo, dei um vexame diante de 4.000 anos de história condensados nas pirâmides.

(8) Para esquecer que hoje é a data mais nefasta do ano, em vez de ficar dando de joão sem braço, escolha uma das opções abaixo e mande ver.

(9) Serjão é um cara que dá a cara pra bater, que briga, que discute.

No presente trabalho, pretendemos identificar a base sintático-semântica que permite derivar todas essas construções, sem, no entanto, acolhermos a ideia de que o verbo 'dar' perde traços estruturais quando passa de um contexto de verbo pleno para um contexto de verbo suporte. Ao explorarmos em nossa análise o modelo de Ramchand (2008), demonstraremos que o verbo pode simplesmente ignorar certos traços na computação, permitindo, assim, a emergência de diferentes significados em diferentes configurações argumentais. É importante destacar que, ao propormos que os variados usos do verbo 'dar' possam ser derivados de uma mesma configuração temática, não estamos nos opondo à ideia de continuum verbal, pois o uso do verbo 'dar' enquanto verbo pleno ou suporte, por exemplo, vai depender também do modo pelo qual o argumento interno do predicado é apresentado. Ou seja, classificar o verbo 'dar' em uma dada categoria depende de outros elementos de composição da sentença, como a pronúncia explícita de seus NPs, conforme é possível notar em "João deu um presente para o Pedro" (compare-se com “*João deu um para o Pedro") e "João deu uma no Pedro" (compare-se com "João deu uma bofetada no Pedro").

$\mathrm{Na}$ próxima seção, apresentamos o aparato teórico a ser utilizado em nossa análise.

\section{Uma proposta para a base sintático-semântica do verbo 'dar'}

Os estudos pioneiros de Fillmore (1968), Jackendoff (1972) e Dowty (1979) colocam os papéis temáticos como uma das mais principais ferramentas das quais o linguista pode lançar mão para entender a relação entre os componentes sintático e 
semântico da gramática. Por muito tempo, assumiu-se que os papéis temáticos (ou papéis semânticos), somados a uma teoria de mapeamento (linking), eram um instrumento produtivo para descrever e explicar a realização sintática dos argumentos verbais. Embora atualmente os papéis temáticos ainda ocupem um lugar de destaque nos estudos gramaticais, a relação entre a seleção argumental do predicado, a função que esses argumentos desempenham no evento e a posição sintática que devem ocupar na sentença é bastante problematizada. Nesta seção, discutiremos os principais problemas que as noções de papel temático e hierarquia temática têm levantado na literatura. Após tal discussão, iremos expor o sistema de Ramchand (2008), que trata de papéis aspectuais, a ser utilizado em nossa análise.

\section{Papéis temáticos e hierarquias temáticas: identificando problemas}

A noção de papel temático remonta aos escritos do gramático indiano Pānini (460 a.C.) que, possivelmente, foi o primeiro estudioso a explorar a correspondência entre propriedades formais de uma língua natural e categorias semânticas do "pensamento" (cf. KASPER, 2008). Para descrever e explicar essa correspondência, Pānini criou uma teoria denominada Kāraka, ou, como a conhecemos atualmente, teoria dos papéis temáticos, utilizada para especificar a interação entre a semântica verbal e a marcação casual atribuída aos argumentos do verbo na sintaxe. Com isso, era possível explicar de um modo sistemático a relação entre as regularidades semânticas de um verbo e suas implicações morfossintáticas. De acordo com Chierchia e McConnell-Ginet (1990, p. 337), o uso dessa noção, tal como a compreendemos e empregamos hoje, entrou para os estudos linguísticos na segunda metade de 1960, com os trabalhos de Gruber (1965) e Fillmore (1968), que buscavam entender quais aspectos semânticos havia em comum nos mais variados usos de um mesmo verbo e quais eram compartilhados por verbos de diferentes classes. Podemos entender melhor a intuição que subjaz essa ideia por meio da análise do seguinte exemplo:

(10) a. Ana fechou a porta com uma chave mestra.

b. Ana fechou a porta.

c. Uma chave mestra fechou a porta. 


\section{d. A porta fechou.}

Ao observarmos um evento no mundo, enquanto falantes de uma língua natural, podemos relatá-lo dos mais diferentes modos (utilizando estratégias linguísticas bastante variadas, como a topicalização e a elisão de argumentos), a depender do destaque que se pretende dar aos elementos nele envolvidos. Por exemplo, ao analisarmos as sentenças em (10), podemos imaginar que um falante, ao proferir (10a), entende que todos os participantes do evento de 'fechar' devam ser destacados. Em vista disso, descreve a cena por ele observada enquanto uma relação transitiva que relaciona alguém que desempenha uma ação (Ana) com um determinado instrumento (com uma chave mestra) para alcançar certo objetivo/resultado (fechar a porta). Por outro lado, um segundo falante que observa a mesma cena pode proferir a sentença em (10b), visando dar destaque apenas ao indivíduo que desempenha a ação de fechar a porta, excluindo de sua descrição, portanto, o instrumento utilizado. A sentença em (10c), por sua vez, pode ser proferida por alguém que considera o instrumento da cena como o elemento principal desse evento, enquanto a sentença em (10d) nada diz sobre o agente e o instrumento, destacando apenas o indivíduo afetado, ou seja, aquele que mantém o resultado final da ação de fechar.

Conforme é possível notar, as quatro sentenças acima diferem em sua sintaxe, mas mantêm uma relação semântica entre si que não parece acidental, pois, por mais que os elementos possam ser alocados em diferentes posições na estrutura, desempenham o mesmo tipo de função em relação ao evento. Em outras palavras, por mais que, por exemplo, 'uma chave mestra' se encontre em (10a) na posição de adjunto e em (10c) na de sujeito, em ambas as sentenças esse argumento desempenhará o papel de instrumento do evento em questão. Dessa observação surgem dois pontos importantes, sendo o primeiro relativo à definição do que seja um papel temático e o segundo relativo à ideia de hierarquia temática: (i) com base no exposto, um papel temático pode ser definido, grosso modo, como uma categoria semântica utilizada para descrever as relações que se estabelecem entre os argumentos de um dado predicado e o evento por ele denotado (essa é a intuição presente na Kāraka de Pānini e também nas teorias mais recentes sobre papéis temáticos); e (ii) os argumentos de um dado predicado não são localizados em posições arbitrárias na sentença, se um determinado argumento aparece ora em posição de adjunção ora na posição de sujeito sintático, tal fato só é possível devido à existência de 
um conjunto de regras que organiza os argumentos na estrutura sintática uns em relação aos outros, tomando como base sua função no desenrolar do evento. Essa questão é conhecida na literatura como "dependência de contexto" (LEVIN; RAPPAPORTHOVAV, 2005) e estabelece que a realização sintática de um argumento não é regida exclusivamente pelo papel temático atribuído a ele, mas também pelos papéis atribuídos a seus argumentos co-ocorrentes. Em suma, os argumentos de um predicado recebem uma função semântica (denominada papel temático) e são organizados na estrutura sintática por meio de regras de mapeamento, que mobilizam o papel desempenhado pelo argumento em relação ao predicado e a dependência de contexto.

$\mathrm{Na}$ literatura, encontramos diferentes listas de papéis temáticos organizados das mais variadas formas. Podemos destacar aqui o trabalho de Belletti e Rizzi (1988), por exemplo, que estipula a existência de apenas três papéis temáticos, ordenados como Agente $>$ Experienciador $>$ Tema. Há, também, o trabalho de Van Valin (1990) que propõe uma grade de seis elementos ranqueados como Agente $>$ Causa $>$ Experienciador $>$ Lugar $>$ Tema $>$ Dativo. Podemos citar, ainda, a proposta de Kiparsky (1985), que organiza uma grade de seis rótulos ranqueando o papel de lugar em uma posição mais baixa do que a de tema (Agente $>$ Origem $>$ Meta $>$ Instrumento $>$ Tema/Paciente $>$ Lugar), diferentemente do que foi sugerido por Van Valin (1990). Conforme é possível observar com essa pequena amostra de listas temáticas organizadas hierarquicamente, além de não haver um consenso na literatura a respeito de quais e quantos papéis a teoria deve assumir como necessários ao sistema, não há acordo também a respeito da ordem em que esses papéis devem ser organizados, e esses são, certamente, os problemas centrais em se trabalhar com a ideia de papel temático.

Quando pensamos no conceito de hierarquia temática, utilizado no mapeamento dos argumentos de um predicado para a sintaxe, encontramos o mesmo tipo de adversidade, pois, por mais que os autores assumam sem maiores objeções a ideia de que o argumento que recebe o papel mais baixo da hierarquia deve ser mapeado para uma posição mais encaixada na sintaxe, ao passo que o argumento que recebe o papel mais alto na hierarquia deve ser mapeado para uma posição mais alta (cf. LARSON, 1988), muitos são os postulados aventados para dar conta dessa relação. Se olharmos novamente para as listas hierárquicas de Belletti e Rizzi (1988), Van Valin (1990) e Kiparsky (1985), podemos notar que o agente é o papel mais propenso a ser mapeado para a posição 
sintática de sujeito; no entanto, na ausência de um argumento agente, para Belletti e Rizzi (1988) o sujeito deve ser ocupado pelo argumento experienciador, para Van Valin (1990) pelo argumento causa e, para Kiparsky (1985), essa posição deve ser preenchida pelo argumento origem. Ou seja, o problema em se definir quais papéis temáticos devem integrar a lista de rótulos necessária para o funcionamento do sistema interfere também no mapeamento dos argumentos para a sintaxe, caso se considere que é o ranqueamento entre os papéis o elemento responsável por mediar a organização argumental na sentença.

É importante mencionar o fato de que o problema de uma ordenação sintática dos argumentos que leve em conta os papéis temáticos permanece mesmo em abordagens que não trabalham com a ideia de hierarquia temática. Baker (1988), por exemplo, propõe uma regra de mapeamento mais absoluta denominada "Hipótese da Uniformidade de Atribuição de Papéis Temáticos" (The Uniformity of Theta Assignment Hypothesis) (UTAH). Para o autor, "relações temáticas idênticas entre os itens são representadas por relações idênticas no nível da estrutura profunda (D-structure)" (RAMCHAND, 2008, p. 7). Basicamente, entende-se que cada papel temático possui uma posição estrutural específica; a título de exemplificação, podemos pensar no papel de agente, que é atribuído, nesse modelo, ao argumento que ocupa a posição de especificador de $v \mathrm{P}$, nesse sentido, argumentos que não estejam nessa posição não podem desempenhar o papel de agente do evento. De acordo com Ramchand (2006), a alternância experienciador-objeto versus experienciador-sujeito levanta sérios problemas para a UTAH, dado que temos um mesmo predicado exibindo relações temáticas diferentes nas posições de sujeito e objeto (ou seja, não parece haver um mapeamento tão uniforme entre estrutura profunda e superficial).
a. O barulho assustou Rui
b. Rui assustou-se com o barulho

Com base nessa discussão, podemos dizer que, de um modo geral, as alternâncias argumentais ferem os postulados feitos pelas regras de mapeamento, pois é possível que um mesmo papel temático apareça em posições sintáticas diferentes, como em "João carregou o caminhão com a mudança" e "João carregou a mudança no caminhão". Infelizmente, os problemas relacionados às noções de papéis temáticos e hierarquias 
temáticas não se limitam às inconsistências entre as teorias ${ }^{8}$ ou às alternâncias argumentais; outro fato que viola sistematicamente as generalizações postuladas pelas regras de mapeamento baseadas em papéis temáticos é a possibilidade de um mesmo verbo aparecer em diferentes quadros de subcategorização, como em "John walked the dog"/“John walked the trail" e "eu peguei uma gripe"/“você precisa pegar a primeira à direita".

Embora os problemas que envolvem a ideia de papéis temáticos sejam muitos, ainda é interessante para nossa teoria de gramática manter e explorar alguns dos insights trazidos por trabalhos como o de Baker (1988), por exemplo. Na próxima seção, apresentaremos o modelo de Ramchand (2008), que é, justamente, uma tentativa de solucionar os problemas aqui elencados.

\section{A Sintaxe de Primeira Fase de Ramchand (2008)}

O trabalho de Ramchand (2008) parte do pressuposto de que é um erro tomar os fatos da estrutura argumental como uma propriedade do léxico ou unicamente do predicado. Isto é, para a autora, os predicados não são capazes de governar todas as generalizações observadas no nível da sentença, mesmo quando combinados a um conjunto de regras de mapeamento. Partindo dessa ideia, Ramchand $(2006,2008)$ propõe que as generalizações a respeito da estrutura argumental existem porque há um correlato direto entre a informação sintático-estrutural e a informação semântica que são disponibilizadas pela composição dos eventos nas línguas naturais. Por conta disso, a autora assume, seguindo Tenny (1987), que o domínio de construção dos eventos é o

\footnotetext{
${ }^{8}$ É importante lembrar que não há um consenso na literatura a respeito de quais papéis devem existir, como se deve definir esses rótulos e não há, também, uma harmonização a respeito da natureza dos papéis temáticos. Por conta dos limites deste trabalho, esta questão não foi discutida, mas podemos resumi-la pensando nos trabalhos de Fillmore (1968) e Dowty (1991). No trabalho de Fillmore (1968), os papéis temáticos (ou casos semânticos) são entendidos como entidades discretas e ordenados em uma lista universal não estruturada, nomeada como "quadro de casos" (FILLMORE, 1968, p. 49) ou "grade theta" (STOWELL, 1981 apud LEVIN; RAPPAPORT-HOVAV, 2005, p. 35). Isto é, cada papel- $\theta$ correspondia a uma unidade primitiva do sistema, podendo a quantidade de papéis existente ser indefinidamente aumentada. Dowty (1991), por outro lado, argumenta que postular papéis temáticos para cada uma das distinções semânticas que possuíam relação com padrões sintáticos acaba por diluir a noção para além de sua utilidade. Em vista disso, propõe que a natureza desses itens semânticos não seja discreta, mas fuzzy, isto é, os papéis temáticos são definidos como "a kind of second order property, a property of multiplace predicates indexed by their argument positions" (DOWTY, 1991, p. 552)" e se resumem a dois "macropapéis", o de "proto-agente" e "proto-paciente".
} 
responsável por definir os papéis temáticos que são necessários para o funcionamento do sistema linguístico e essa definição se dá em função de propriedades aspectuais contidas no predicado $^{9}$. Ou seja, dada uma sentença transitiva qualquer, se não encontramos uma língua na qual o argumento agente é realizado na posição de objeto, ao passo que o paciente é realizado na posição de sujeito, tal fato não se dá por propriedades do léxico ou das regras de mapeamento, mas sim por fatores aspectuais, diretamente ligados à estrutura sintática.

Seguindo os pressupostos da Nanossintaxe (cf. STARKE, 2009), Ramchand (2008) propõe a existência de uma estrutura mais articulada para o domínio dos eventos $(v \mathrm{P})$. No modelo em questão, denominado Sintaxe de Primeira Fase ${ }^{10}$, as generalizações selecionais são vistas como submissas à representação em termos de uma sintaxe articulada com uma interpretação semântica sistemática. Esse sistema permite uma simplificação radical da arquitetura da gramática, pois elimina o léxico como um módulo com regras e operações próprias e desloca o núcleo computacional integralmente para a sintaxe, limitando a flexibilidade do item verbal e as generalizações a seu respeito a esse único componente. Podemos dizer, desse modo, que a competência linguística inclui, mínima e crucialmente, um único sistema combinatório a partir do qual as sentenças são construídas com apenas um conjunto de primitivos e um conjunto de operações.

Os primitivos em questão são noções aspectuais submorfêmicas baseadas na noção de causação: como os falantes percebem os eventos em termos de um desencadeamento que causa um processo e culmina em um resultado; para Ramchand (2008) é seguro pensar na configuração dos traços do domínio verbal como uma generalização dessa intuição. Com base nessa ideia e em uma extensa pesquisa empírica translinguística, a autora estabelece a existência de três elementos aspectuais fundamentais para a composição eventiva: iniciação [init], processo [proc] e resultado [res], que, conforme dissemos anteriormente, são amarrados a uma representação

\footnotetext{
${ }^{9}$ As propriedades aspectuais que serão mencionadas nesta seção se referem a propriedades relacionadas ao que se conhece na literatura por "aspecto lexical" ou aktionsart. Não abordaremos, portanto, questões relativas ao aspecto gramatical perfectivo e imperfectivo.

${ }^{10} \mathrm{O}$ nome do modelo é derivado de dois pressupostos: (a) a sintaxe é o único e verdadeiro componente gerativo (STARKE, 2009); e (b) o domínio de construção de eventos é o responsável por fazer a mediação entre as relações argumentais e as posições estruturais disponíveis na sintaxe. Grosso modo, podemos dizer que, para Ramchand (2008), há uma prioridade lógica da porção de construção do evento de uma proposição em relação à concordância, tempo, checagem/marcação de caso e modificação em geral. Por esse motivo, a autora estabelece que o domínio de construção de eventos é a "primeira fase" da derivação das sentenças na sintaxe.
} 
sintática, tal como se observa na figura abaixo.

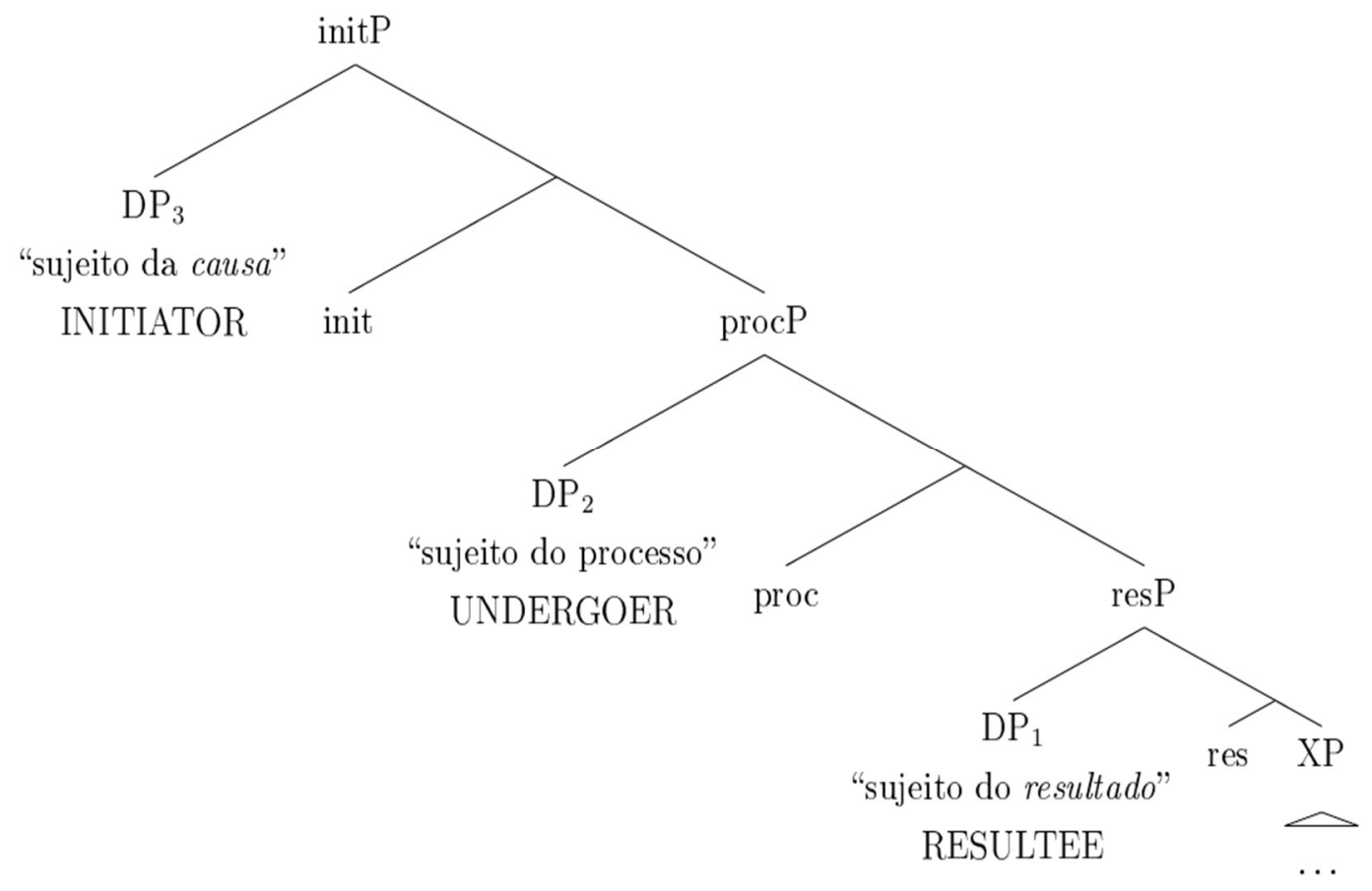

Essa hierarquia rica e articulada para os elementos que compõem os eventos é também delineada para capturar estruturalmente um conjunto de papéis semânticos que identifica a função que cada argumento desempenha no desenrolar do evento. Esses papéis são atribuídos aos argumentos localmente (em spec-XP) e podem ser entendidos do seguinte modo: qualquer argumento que seja responsável por dar início à eventualidade pode ser interpretado como INITIATOR em spec-initP. Essa propriedade, de acordo com Ramchand (2008), é sintaticamente relevante, pois subjaz argumentos agentivos, volitivos ou experienciadores. Para a autora, embora a agentividade pareça ser uma categoria importante para identificar a felicidade de certas sentenças, a propriedade que pode determinar classes relevantes é a de iniciador; é por meio dela, por exemplo, que a distinção entre predicados inergativos e inacusativos pode ser estabelecida: inacusativos não são capazes de projetar um núcleo de iniciação, logo, não poderão ter um argumento INITIATOR. O próximo papel relevante na estrutura é o de UNDERGOER ou sofredor, que pode ser atribuído, em spec-procP, a qualquer argumento que sofra ou passe por um processo de mudança dinâmica. A mudança, aqui, é entendida de um modo bastante genérico, podendo ser estendida para mudanças de estado (graduais ou não), mudanças nas propriedades do argumento ou até mesmo mudanças espaciais, com 
deslocamento de posição. O rótulo de RESULTEE, ou de resultado, por fim, pode ser atribuído, em spec-resP, ao argumento que na eventualidade detiver um estado final. Tendo em vista esses rótulos e os núcleos de iniciação, processo e resultado, cada projeção forma sua própria estrutura predicacional, sendo a posição de especificador preenchida pelo argumento que desempenha o subevento e a posição de complemento saturada pelo sintagma que descreve ("oferece o conteúdo de") esse subevento. As três relações principais que se estabelecem na estrutura são resumidas por Ramchand (2008) do seguinte modo:

i. initP introduz o evento de causação e licencia o argumento externo ('sujeito' da causa $=$ INICIADOR (INITIATOR));

ii. procP especifica a natureza da mudança ou do processo e licencia a entidade submetida à mudança ou ao processo ('sujeito' do processo $=$ SOFREDOR (UNDERGOER));

iii. resP provê o 'o estado resultante' do evento e licencia a entidade que mantém o estado resultante ('sujeito' do resultado $=$ RESULTADO (RESULTEE))

Antes de expormos as regras que permitem construir sentenças a partir de initP, procP e resP, é importante dizer que na Sintaxe de Primeira Fase não há uma correspondência única entre itens utilizados na composição das sentenças e núcleos sintáticos. Nesse modelo, um mesmo item de vocabulário pode ocupar mais do que um terminal, ou seja, é possível que um morfema percorra diferentes núcleos sintáticos, correspondendo, assim, a uma subárvore completa. O morfema '-ei', retirado de "cantei”, por exemplo, carrega a estrutura Tempo $>$ Aspecto $>$ Modo, i.e., '-ei' "percorre” diferentes posições na estrutura sintática. Por conta desse fato, um argumento do tipo INITIATOR pode também ser indexado ao papel de UNDERGOER caso não apenas inicie o evento, mas também seja afetado por ele em seu desenrolar: o argumento Ana, em "Ana correu", não apenas dá início à atividade de correr, como também é o argumento que passa por um deslocamento/uma mudança de lugar. Desse modo, Ana desempenha o papel composto de [INITIATOR $i$, UNDERGOER $_{i}$ ] em 'correr'.

Para evitar uma teoria que possa sobregerar estruturas inexistentes nas línguas naturais, o modelo é regido por uma série de princípios, dentre os quais destacamos 
apenas três: (i) o Teorema *ABA, que diz respeito a certas propriedades de localidade, (ii) a Condição de Âncora e (iii) a regra de Subassociação dos itens. De acordo com Pantcheva (2011), o Teorema *ABA atua como uma espécie de restrição de localidade, impossibilitando que um determinado item identifique duas posições não adjacentes. Por exemplo, dada a articulação dos traços [dativo $>$ feminino > plural], um item A que identifique [plural] não pode identificar também [dativo] sem realizar a posição intermediária de [feminino]. Tal geometria geraria a estrutura ABA, que parece ser sistematicamente bloqueada entre as línguas naturais. A Condição de Âncora, encontrada no trabalho de Caha (2009), estabelece, com base em investigação empírica, que o traço mais baixo de uma dada hierarquia deve, necessariamente, ser realizado na operação de Spell-out, ou seja, não é possível que o item mais encaixado da estrutura seja ignorado na computação. A regra de Subassociação dos itens, por fim, prediz que certos traços da estrutura podem ser não computados na derivação, ficando subassociados a outro traço imediatamente adjacente. Para que tal processo seja licenciado, é necessário que o traço seja independentemente identificado dentro da fase de derivação e apresente conteúdo enciclopédico compatível com o terminal no qual ficará representado.

Conforme é possível observar, com o modelo de Ramchand (2008) conseguimos solucionar os problemas elencados na seção anterior. Na Sintaxe de Primeira Fase, há apenas três papéis temáticos que são motivados pela estrutura do evento que os predicados denotam - não há uma lista aberta e indefinida de papéis que possam compor o inventário necessário para a interpretação sentencial. Além disso, esses papéis são definidos de modo a incorporar apenas noções que são empiricamente relevantes para o comportamento verbal, tais como a de iniciador e sofredor. Outro ponto fundamental é o fato de Ramchand (2008) assumir que os argumentos são diretamente inseridos na estrutura sintática, o que permite uma simplificação radical do sistema, eliminando, por exemplo, a necessidade de se estabelecer regras de mapeamento dos argumentos para posições específicas na sintaxe. A proposta da autora, de certo modo, implementa a intuição mais geral da UTAH de Baker (1988) de que a correlação entre estrutura sintática e significado é mais direta do que se supõe. Por conta da inexistência de regras de mapeamento em Ramchand (2008), a hierarquia é dada pela própria estrutura, de tal modo que o argumento mais baixo será sempre localizado em uma posição mais encaixada na sintaxe e o argumento mais alto será sempre encontrado em uma posição mais alta, como a de sujeito. A grande 
questão é, desse modo, compreender que os argumentos não serão mapeados para a sintaxe a depender de sua função no evento porque eles são diretamente inseridos em núcleos aspectuais na sintaxe, assim, as posições de sujeito e objeto (direto e indireto) serão associadas à hierarquia imposta pela própria estrutura.

Antes de iniciarmos nossa análise e demonstrarmos como esse modelo pode ser explorado na explicação dos diferentes usos do verbo 'dar', podemos discorrer brevemente sobre como a Sintaxe de Primeira Fase consegue lidar com a flexibilidade e a rigidez próprias do domínio verbal. Os exemplos dados anteriormente "John walked the dog"/“John walked the trail” são analisados por Ramchand (2006, p. 14) como derivados de uma mesma estrutura [INITIATOR , UNDERGOER ${ }_{i}$ ] exemplificada por “John walks". De acordo com a autora, em todas as três sentenças o predicado 'walk' identifica os núcleos de iniciação e processo, porém, a posição temática que licenciam é identificada por argumentos distintos em cada situação, de tal modo que em "John walked the dog" o argumento "John" atua como o INITIATOR e o argumento "the dog" atua como o UNDERGOER, havendo, assim, uma subassociação do papel original de UNDERGOER que resulta em [INITIATOR, UNDERGOER]. No último exemplo, "John walked the trail", "John" recebe o papel composto de [INITIATOR $\mathrm{i}$, UNDERGOER $_{\mathrm{i}}$ ] e o sintagma "the trail" é um elemento remático não aspectual, que apenas contribui para a descrição do evento, estabelecendo uma relação de figura e fundo com o argumento sujeito. É com base nessas ideias que apresentamos, a seguir, nossa proposta sintático-semântica para o verbo 'dar'.

\section{Uma proposta de hierarquia para o verbo 'dar'}

Nossa proposta é a de que os diferentes usos do verbo 'dar' possam ser, na verdade, decorrentes de apenas uma grade temática, que pode ser diferentemente atualizada de três modos de acordo com a quantidade de argumentos presentes na sentença. Com isso, evitamos o apelo à proliferação de significados ou ambiguidades e podemos oferecer um tratamento refinado para o verbo em análise, que apresente, sobretudo, adequação teórica e plausibilidade psicológica, especialmente quando pensamos no processo de aquisição da linguagem. Uma vez que a criança pode ter como input apenas um verbo 'dar' e derivar dessa estrutura diferentes significados, por meio de 
generalizações previstas por regras da Gramática Universal (GU), há uma grande economia no processo de aquisição que é desejável em qualquer teoria da gramática.

Tendo isso em vista, em (I) representamos a grade temática do uso canônico do verbo 'dar', que expressa transferência de posse; em (II) representamos a grade de usos que expressam uma relação entre dois argumentos, tal que o primeiro (sujeito) tem como resultado ou "dá lugar" ao segundo (objeto); em (III) é representada a grade de usos que denotam apenas um "resultado".

(I) $\quad$ INITIATOR $>$ UNDERGOER $>$ RESULTEE

(II) UNDERGOER $>$ RESULTEE

(III) RESULTEE

Na próxima seção, colocaremos nossa proposta à prova e demonstraremos como a Sintaxe de Primeira Fase (RAMCHAND, 2008) contribui para a análise dos diferentes usos do verbo 'dar'.

\section{Analisando os exemplos}

A estrutura temática que propomos para o verbo 'dar' dá conta naturalmente de sentenças como (12), (13), (14) e (15):

(12) João deu um presente para Maria.

(13) A cachorrinha deu seis filhotes aos donos.

(14) Maria deu um chute na quina da porta.

(15) Em 2010, dei mais tempo para mim mesma.

Nessas sentenças, o sujeito (seja ele fonologicamente realizado ou não), por ter um papel no desenrolar do processo, é o INITIATOR; o objeto direto é o UNDERGOER, por ser o argumento que passa pelo processo dinâmico de transferência de posse; e o argumento preposicionado é o RESULTEE, dado que mantém (ou adquire) como consequência do evento uma certa propriedade estativa. $\mathrm{O}$ argumento que atua como RESULTEE, mais especificamente, recebe do INITIATOR um determinado objeto que 
está (ou fica) em sua posse ao final do evento. Para Ramchand (2008), o núcleo de resultado identifica o estado final de um processo pontual, por esse motivo, sentenças que sejam incompatíveis com o adjunto 'por x tempo' indicam a existência de um argumento RESULTEE integrando sua grade temática. Conforme podemos averiguar nos exemplos abaixo, de fato as sentenças de (12) a (15) não podem ser combinadas ao adjunto em questão.

(12) *João deu um presente para Maria por duas horas.

(13) *A cachorrinha deu seis filhotes aos donos por um ano.

(14) *Maria deu um chute na quina da porta por 10 minutos.

(15) *Em 2010, dei mais tempo para mim mesma por duas horas.

A hierarquia (I) apresentada na seção anterior, exemplificada por INITIATOR > UNDERGOER > RESULTEE, explica as relações semânticas que se estabelecem não apenas entre os argumentos dos usos transitivos do verbo 'dar' (cf. (12)-(15)), mas também certos usos que são tidos pela literatura como sendo de verbo-suporte (RASSI; VALE, 2013). Na sentença (16) abaixo, retirada da seção “Os vários usos do verbo 'dar”", entendemos "o Conde INITIATOR deu [garantias da melhora da infraestrutura] UNDERGOER ØRESULTEE", ou seja, por mais que não haja na posição de spec-resP um argumento fonologicamente explícito, há a interpretação de que as garantias foram dadas a alguém. Outra sentença também identificada como sendo de um uso suporte do verbo 'dar' e que pode ser explicada pela mesma grade temática é apresentada em (17). Nessa construção, embora não haja um argumento que receba o UNDERGOER por meio de um processo de transferência pontual, entendemos que o argumento introduzido por preposição "o terceiro mandato consecutivo do PT na capital gaúcha" surge como consequência do evento dinâmico. Desse modo, simplificando a sentença, temos que "Pont INITIATOR deu inícioundergoer a[o terceiro mandato] RESUltee". Com isso, já demonstramos que uma mesma grade temática perpassa diferentes classes do continuum.

(16) Conde falou da transformação do Rio e deu garantias da melhora da infraestrutura.

(17) Pont deu início ao terceiro mandato consecutivo do PT na capital gaúcha. 
O uso transitivo (biargumental) de 'dar' não trata do INITIATOR, mas expressa uma relação entre dois argumentos localizados em posições mais baixas na hierarquia postulada em (I); podemos sustentar essa hipótese por meio da análise dos seguintes exemplos, que expressam, basicamente, resultados de alguma operação.

(18) 10 menos 2 dão 8 .

(19) A conta deu 30 reais.

Nessas sentenças, encontramos uma grade temática que é um subconjunto de (I). Mais especificamente, é a hierarquia exibida em (II) que dá conta de explicar os usos biargumentais de 'dar'. Basicamente, interpretamos que o argumento em posição de sujeito em (18) e (19) é submetido a uma operação matemática de soma, que nada mais é do que um processo dinâmico. Desse modo, o sujeito dessas sentenças desempenha o papel de UNDERGOER da eventualidade, que tem como resultado pontual o argumento localizado na posição de objeto direto. Por conta dessa relação, "8" em (18) e "30 reais" em (19) são interpretados como o RESULTEE da eventualidade; prova de que esse é de fato o caso é a incompatibilidade dessas sentenças com o adjunto 'por x tempo', conforme é possível observar nas sentenças abaixo.

(21) *10 menos 2 dão 8 por muito tempo.

(22) *A conta deu 30 reais por duas horas.

É interessante notar que o papel ignorado na computação quando há menos argumentos na sentença é o de INITIATOR. Tal fato pode ser explicado dentro da Sintaxe de Primeira Fase (RAMCHAND, 2008) considerando-se o Teorema *ABA e a Condição de Âncora. De acordo com esta condição, o argumento mais baixo da hierarquia não pode ser não computado na derivação de uma sentença e, de acordo com o teorema, funções não adjacentes não podem ser identificadas pelo mesmo item de vocabulário. Como consequência, considerando que o verbo 'dar' carrega uma configuração estrutural do tipo [iniciação $>$ processo $>$ resultado], quando temos apenas dois argumentos na sentença, os compostos [iniciação $>$ resultado] e [iniciação $>$ processo] são sistematicamente não permitidos. Isso porque o traço de resultado, por ser o mais baixo da hierarquia, deve ser 
necessariamente utilizado na derivação, impedindo a configuração [iniciação > processo]; e, pelo fato de os núcleos de iniciação e resultado não estarem localizados na adjacência um do outro, a formação de [iniciação > resultado] é também impedida. Caso adotássemos para a análise do verbo 'dar' uma teoria de papéis temáticos que utiliza um componente de mapeamento dos argumentos para a sintaxe, não conseguiríamos explicar, com mecanismos independentemente motivados, o porquê de as relações temáticas se estabelecerem da maior grade de relações para a menor. Ou seja, caso não houvesse no sistema regras rígidas de computação, não haveria como garantir que as relações relevantes para a compreensão dos diferentes usos do verbo 'dar' são essas e não outras.

A última grade temática de 'dar' está relacionada ao uso monoargumental desse verbo e expressa unicamente um resultado, tal fato é, também, uma consequência das regras do modelo adotado para a análise. Conforme é possível observar nas sentenças de (23) a (26) abaixo, há um único argumento que é interpretado como RESULTEE. Nesses usos do verbo 'dar' não se explicita a existência de um processo que leva a um resultado, há apenas o destaque para a porção final de um dado evento.

(23) Deu duas horas.

(24) Hoje no meu show deu mil pessoas.

(25) A fruta deu bolor.

(26) Esse fim de semana vai dar praia.

Nas sentenças de (24) a (26), encontramos casos em que o argumento na posição de sujeito sentencial não é de fato argumento externo do verbo. "Hoje no meu show" é simplesmente um sintagma composto que indica o tempo e o lugar nos quais o evento ocorreu; "a fruta" em (25) é o local onde "deu bolor"; e, por fim, "esse fim de semana" em (26) quantifica temporalmente o evento, sendo, portanto, apenas um adjunto temporal tal qual "hoje" em (24). Ou seja, o que observamos na posição de sujeito nas sentenças acima é o resultado de alguma operação localizada fora da Primeira Fase (RAMCHAND, 2008), que pode envolver topicalização (24) e a construção de sentenças médias ((25)(26)). No domínio sintático-semântico de atribuição temática, temos “deu duas horasresultee", "deu mil pessoasresultee no meu show hoje", "deu bolor Resultee na fruta" e "vai dar praiaResultee nesse fim de semana". Com isso, esperamos ter 
demonstrado que o argumento que aparece na posição de sujeito das sentenças acima não atua no evento como um INITIATOR, mas integra a descrição não aspectual do evento de forma substancial, especificando certas informações de tempo e lugar.

Tendo sidos expostos os dados, nossa análise pode ser pensada como um algoritmo que parte de uma grade temática ampla, que pode instanciar outras possibilidades acarretadas por ela de um modo sistemático, a depender da quantidade de argumentos expressos na estrutura. Desse modo, essas outras possibilidades são alcançadas por meio do princípio mais básico que rege a ideia de hierarquia temática dentro na Sintaxe de Primeira Fase (RAMCHAND, 2008). Tendo isso em vista, podemos descrever esse algoritmo para lidar com as diferentes interpretações do verbo 'dar' do seguinte modo:

(a) havendo três argumentos presentes, um deles será o INITIATOR (posição sintática de sujeito), outro UNDERGOER (posição de objeto direto) e o terceiro o RESULTEE (posição de objeto preposicionado), como no esquema (I);

(b) havendo dois argumentos na estrutura, um deles será o UNDERGOER e o outro o RESULTEE; sendo o argumento UNDERGOER destinado para a posição sintática de sujeito e o RESULTEE para a posição de objeto direto, como no esquema (II);

(c) havendo apenas um argumento, seu papel será o de RESULTEE, destinado a ocupar a posição sintática de objeto direto, como no esquema (III).

Acreditamos que o funcionamento do algoritmo aqui proposto tenha sido averiguado e justificado com a análise das sentenças acima. No entanto, cabe ainda tratarmos de alguns pontos para concluirmos nossa análise. Primeiramente, é interessante observar que o uso canônico do verbo 'dar' é exclusivamente veiculado por sentenças com a grade temática de (I), descrita mais detalhadamente por (a), porém, há alguns casos de usos (semi-)fixos, que seriam a última etapa do continuum, que também são veiculados por três argumentos, como se observa em (27).

(27) Pe. Pio deu na cara de um fiel. 
Nessa estrutura, cujo argumento interno é um UNDERGOER não pronunciado, temos uma espécie de evento de transferência canônico, haja vista que a posição de objeto direto pode ser preenchida por sintagmas como 'um tapa' ou 'um tabefe', que "são recebidos pelo fiel". Ou seja, "Pe. Pio Initiator deu $\varnothing_{\text {Undegoer }}$ n[a cara de um

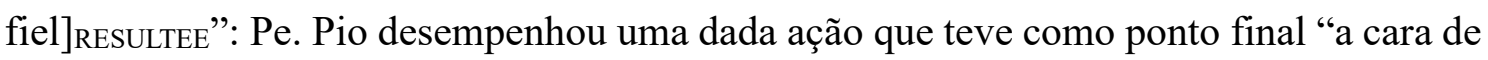
um fiel". Pensando nas condições de verdade dessa sentença, dificilmente interpretaríamos que Pe. Pio deu um beijo na cara de um fiel e esse fato levanta uma questão interessante a respeito dos usos (semi-)fixos do verbo 'dar'. Normalmente, expressões como "dar uma em" ou "dar para" são utilizadas em contextos relacionados a situações de violência ou relativas à prática sexual (cf. (28) e (29) abaixo). Desse modo, a elisão do argumento UNDERGOER em certos usos do 'dar' pode ser não acidental, mas um modo de amenizar o conteúdo da informação que se pretende veicular.

(28) Ou você fica quieto ou te dou uma!

(29) Ana deu pro Rui.

Ao lado das interpretações que o algoritmo aqui proposto gera e dos usos (semi-)fixos que podem ser a ele relacionados, é interessante mencionarmos também o uso modal de 'dar', como nos exemplos (30) e (31), por ainda apresentarem um certo grau de composicionalidade, podendo, assim, ser entendidos sem apelarmos para ambiguidades lexicais. Nota-se, nessas sentenças, um uso bastante próximo ao “resultativo", e sua estrutura é sempre 'dar de/pra + INFINITIVO'.

(30) Essa construção dá pra/de fazer bonito, né?!

(31) Esse menino dá pra professor.

Considerando as interpretações geradas pelo algoritmo aqui proposto, e as estruturas semi-fixas nas quais aparece o verbo 'dar', como as exemplificadas acima, e que cabem em nossa proposta, é possível dar conta, composicionalmente, de um número bastante significativo de interpretações do verbo 'dar'. Na próxima seção, elaboramos um breve balanço dos resultados alcançados. 


\section{Conclusão}

Neste artigo, partimos da constatação empírica de que o verbo 'dar' é um dos mais produtivos, versáteis e frequentes do português brasileiro atual. Um rápido olhar em alguns dos principais dicionários de português traz a enorme gama de significados diferentes que o verbo 'dar' e as construções nas quais ele participa apresentam. Partindo da ideia de que tais significados não são o resultado de ambiguidades, mas sim estão relacionados, procuramos dar conta de alguns deles através da postulação de uma grade temática para o verbo 'dar' baseada na Sintaxe de Primeira Fase desenvolvida por Ramchand (2008), de modo a gerar sistematicamente vários dos significados trazidos pelos dicionários, e correntes no uso da língua. Nossa proposta, que pode ser entendida como um algoritmo, postula uma estrutura de base com três argumentos (um INITIATOR, um UNDERGOER e um RESULTEE); na ausência do INITIATOR, o UNDERGOER ocupa a posição de sujeito, dado que a hierarquia se dá pela própria estrutura sintática; na ausência também de um UNDERGOER, temos apenas um RESULTEE. Mostramos também que essa ideia dá conta de alguns significados de construções semi-fixas em que figura o verbo 'dar'.

Obviamente, não é possível dar conta de todos os casos, entre outras coisas porque algumas das construções fixas e/ou semi-fixas parecem envolver diferentes atribuições de cadeia temática, embora se aproximem bastante do uso canônico do verbo. Tomemos, por exemplo, 'dar-se por ADJ' (como em "João deu-se por perdido"): nesse caso, é possível perceber a existência de um sujeito iniciador, o 'João', um tema, expresso pelo 'se' reflexivo, e um resultado, veiculado 'por ADJ'. Afinal, 'perdido' é a característica atribuída ao tema pelo desencadeador. Essa mesma análise pode ser estendida a 'dar uma de' (como em "Maria deu uma de 'joão sem braço"'): nesse caso, Maria seria o iniciador, 'uma de' pode evocar uma atitude ou comportamento, sendo interpretada como UNDERGOER, e ‘joão sem braço’ funcionaria como o resultado. É interessante, ainda, perceber que essa sentença pode ter um RESULTEE, como em "ele deu uma de idiota pra cima de mim". Todas essas expressões fixas, então, se aproximariam mais do uso canônico do verbo.

Seja como for, com uma teoria mínima, baseada em conceitos independentemente motivados, é possível lidar com uma proliferação de significados aparentemente não relacionados entre si, e foi isso o que fizemos neste artigo. 
FERREIRA, Thayse Letícia; RASSI, Amanda Pontes; BASSO, Renato Miguel. The interpretations of the verb ' $d a r^{\prime}$ [to give] and its thematic structure: a syntactic-semantic analysis. Revista do GEL, v. 14, n. 2, p. 76-104, 2017.

Abstract: In this paper, we present a proposal to analyze some of the possible interpretations of the verb 'dar' [to give], based on the concepts of thematic roles and thematic hierarchy. Our analysis allows us to deal with a large amount of interpretations of this verb, by using independently motivated tools, considering a basic thematic grid and a hierarchy that allows generating other interpretations besides the canonical one, with three arguments. In the end, we link our proposal to some fixed and semifixed structures of the verb 'dar' [to give].

Keywords: Thematic roles. Thematic hierarchy. Verb semantics.

Submetido em: 19/09/2016.

Aceito em: 10/07/2017.

\section{Referências}

BAKER, M. Incorporation: A Theory of Grammatical Function Changing. Chicago: University of Chicago Press, 1988.

BELLETTI, A.; RIZZI, L. Psych-Verbs and $\theta$-theory. Natural Language and Linguistic Theory, v. 6, p. 291-352, 1988.

CAHA, P. The nanosyntax of case. 2009. $334 \mathrm{f}$. Tese (PhD), University of Tromsø, Tromsø, 2009.

CHIERCHIA, G.; McCONNELL-GINET, S. Meaning and Grammar: An Introduction to Semantics. Cambridge: The MIT press, 1990.

CHOMSKY, N. Regras e representações. Rio de Janeiro: Zahar, 1981.

DICIO - Dicionário Online de Português. Disponível em: $<$ http://www.dicio.com.br $>$. Acesso em: 03 ago. 2016.

DICIONÁRIO PRIBERAM DA LÍNGUA PORTUGUESA. 2008-2013. Disponível em: $<$ http://www.priberam.pt/dlpo/dar>. Acesso em: 03 ago. 2016.

DOWTY, D. Word Meaning and Montague Grammar. The Semantics of Verbs and Times in Generative Semantics and Montague's PTQ. Dordrecht: Reidel, 1979. 619, 1991.

Thematic Proto-roles and Argument Selection. Language, v. 67, n. 3, p. 547- 
FERREIRA, A. B. de H. Aurélio século XXI: o dicionário da Língua Portuguesa. 3. ed. rev. e ampl. Rio de Janeiro: Nova Fronteira, 1999.

FILLMORE, C. The case for case. In: BACH, E.; HARMS, R. T. (Eds.). Universals in Linguistic Theory. New York, 1968.

GROSS, G. Un cas des constructions inverses: donner et recevoir. In: Linguistica e Investigationes, v. 6, n. 1, Amsterdam-Philadelphie: J. Benjamins B.V., p. 1-44, 1982.

GRUBER, J. S. Studies in Lexical Relation. 1965. 310 f. Tese (Doutorado em Línguas Modernas e Linguística) - Instituto de Tecnologia de Massachusetts, Cambridge, Massachusetts, 1965.

HOUAISS, A.; VILLAR, M. de S. Dicionário Houaiss da Língua Portuguesa. Rio de Janeiro: Objetiva, 2001.

JACKENDOFF, R. Semantic Interpretation in Generative Grammar. Cambridge: MIT Press, 1972.

KASPER, S. A comparison of 'thematic role' theories. 2008. $181 \mathrm{f}$. Dissertation (Magister-Hausarbeit im Fach "Deutsche Sprache") - Fachbereich Germanistik und Kunstwissenschaften der Philipps-Universität Marburg, Marburg, 2008.

KIPARSKY, P. Morphology and Grammatical Relations. Unpublished Ms. Stanford, 1985.

LARSON, R. K. On the double object construction. Linguistic Inquiry, v. 19, p. 335391, 1988.

LEVIN, B.; RAPPAPORT-HOVAV, M. Argument Realization. New York: Cambridge University Press, 2005.

MICHAELIS: moderno dicionário da língua portuguesa. São Paulo: Companhia Melhoramentos, 1998 (Dicionários Michaelis).

NEVES, M. H. M. Estudo das construções com verbo-suporte em português. In: KOCH, I. G. V. (Org.). Gramática do Português Falado VI: Desenvolvimentos. Campinas: Editora da UNICAMP, 1996.

PANTCHEVA, M. Decomposing Path: The Nanosyntax of Directional Expressions. 2011. 303 f. Tese (PhD), University of Tromso, 2011.

RAMCHAND, G. Against a generative lexicon. Handout. University of Geneva, 2006. 2008. . Verb Meaning and the Lexicon. Cambridge: Cambridge University Press, 
RASSI, A. P.; VALE, O. A. Tipologia das construções verbais do Português do Brasil: uma proposta de classificação do verbo dar. In: CAMBRAIA, C. N. et al. (Org.).

Caligrama: Revista de Estudos Românicos, v. 18, n. 2, p. 105-130, 2013.

STARKE, M. Nanosyntax: A short primer to a new approach to language. Nordlyd, v. 36, n. 1: Special issue on Nanosyntax, 2009.

TENNY, C. Grammaticalizing aspect and affectedness. PhD thesis, MIT, 1987.

VALE, O. A. Expressões cristalizadas do português do Brasil: uma proposta de tipologia. 2001. 213 f. Tese (Doutorado em Linguística e Língua Portuguesa) Faculdade de Ciências e Letras, Universidade Estadual Paulista, Araraquara, 2001.

VAN VALIN Jr., R. D. Semantic Parameter of Split Intransitivity. Language, v. 66, p. 221-260, 1990. 